\title{
Designing an institutional network for improving farm animal welfare in the EU
}

Article

Accepted Version

Jones, P., Lensink, J., Mancini, M. C. and Tranter, R. (2017) Designing an institutional network for improving farm animal welfare in the EU. Journal of Common Market Studies, 55 (5). pp. 1081-1093. ISSN 1468-5965 doi:

https://doi.org/10.1111/jcms.12547 Available at https://centaur.reading.ac.uk/69106/

It is advisable to refer to the publisher's version if you intend to cite from the work. See Guidance on citing.

To link to this article DOI: http://dx.doi.org/10.1111/jcms.12547

Publisher: Wiley

All outputs in CentAUR are protected by Intellectual Property Rights law, including copyright law. Copyright and IPR is retained by the creators or other copyright holders. Terms and conditions for use of this material are defined in the End User Agreement.

\section{www.reading.ac.uk/centaur}

\section{CentAUR}

Central Archive at the University of Reading 
Reading's research outputs online 


\section{Designing an institutional network for improving farm animal welfare in the EU}

Philip Jones $^{a}$, Joop Lensink ${ }^{b}$, Maria Cecilia Mancinic and Richard Tranter ${ }^{a}$

a University of Reading; ${ }^{\mathrm{b}}$ Institut Supérieur d'Agriculture, Lille; ${ }^{\mathrm{c}}$ Università degli studi di Parma.

Correspondence:

Professor Richard Tranter

Centre for Agricultural Strategy, University of Reading

Earley Gate, Reading, RG6 6AR, UK.

Tel: +44(0)118378 8155

email: r.b.tranter@reading.ac.uk

\section{Abstract}

Improvements in the welfare of farmed animals in the EU have been achieved by legislation, increased welfare capacity in the food chain, greater public awareness, welfare measurement tools and dissemination of best practice. However, pressure for improvement grows. The EC recognises that delivering improved welfare would best be achieved by increasing welfare capacity, including establishing a Network of Welfare Reference Centres to provide support for welfare research, knowledge transfer and policy design. Designing a structure for this Network presents a challenge, as it would have multiple functions, interact with diverse stakeholders and operate in a complex environment. Here, we describe the use of a novel strategic planning approach to design an optimal structure for this Network. Our evaluation found that no existing structure was ideal, but that by taking functional units from several existing models, an optimal model could be identified.

Keywords: animal welfare; network of Reference Centres. 
Acknowledgement: The European Commission's DG SANCO for funding the work reported here.

Running head: Improving farm animal welfare in the EU.

Introduction

Legislation to prevent cruelty, reflecting societal expectations and producer realities, coupled with monitoring and enforcement by governments, is the foundation of farmed animal welfare protection across the EU (European Commission, 2007a; Bennett and Appleby, 2010). These interventions, for example EU Directive 98/58/EC, are undertaken where there is deemed to be a failure of the market to deliver the minimum welfare standards demanded by EU citizens. One reason for market failure is that because evidence of poor welfare is not apparent in products the welfare capacity of the market is too limited. For example, if food marketing chains are not sufficiently developed to provide information about the welfare standards under which products are produced, consumers cannot make informed choices based on welfare provenance (FAWC, 2009; Mancini and Arfini, 2012).

A number of drivers of change in the welfare 'capacity' of the food chain have taken place since the EU Protocol on Animal Welfare of 1997 (Bennett and Appleby, 2010). These include, on the supply side: new systems for measuring welfare; improved farmer awareness and training; and animal husbandry technologies. On the demand side, public awareness of, and concern for, animal welfare has increased. The market has responded to these developments by instituting a range of welfare capacity enhancing measures, including: voluntary welfare codes; corporate social responsibility programmes; codes of practice for private sector food procurement; product labelling/certification schemes; and international agreements. 
While the above market and legislative measures have broadly improved welfare, some suboptimal welfare persists due to failure to comply with existing measures, either through avoidance, or management failures, as reported in a seminal article by Broom (1991). To illustrate, for the UK, FAWC (2009) reported a persistent level of non-compliance with welfare legislation. The FAO (Fraser et al., 2009) have argued that further improvement in welfare will only result from increasing the uptake of existing voluntary schemes and minimising avoidance of statutory minima, through increasing the welfare capacity of the food chain, for example through: education; engagement; training; and communication.

The EU 'Community Action Plan on the Protection and Welfare of Animals 2006-2010' (EC, 2006) suggested that welfare capacity building in the food chain should involve upgrading minimum standards, standardisation of animal welfare indicators, training animal keepers and raising public awareness. In recognition of the cross-cutting and international nature of welfare issues, the Action Plan also identified the need for the establishment of a European Centre for the co-ordination of welfare-promoting activities.

Responding to this, the EC (2009), considering the organisational structure of this future Centre, argued that existing EU institutions involved with welfare, such as the European Food Safety Authority or the EC Joint Research Centre, were inadequate to fulfil this role. What was needed, therefore, was the establishment of a Network of smaller Reference Centres, rather than a single large centre, to 'provide technical support for developing animal welfare policies including certification and labelling'. In response, the European Parliament (2009) proposed that such a co-ordinated Network of Centres for animal welfare might be set-up incorporating existing Community or Member State institutions, one of which would be designated as the Coordinating Body. 
The EC (2013) issued a new proposal, updating their 2009 proposal, to provide the legal basis for the establishment of the Network of Reference Centres through a regulation to update Regulation (EC) 882/2004 which provides the legislative framework for organising official controls to ensure the verification of compliance with animal health and welfare rules and the establishment of the Network of Reference Centres. The 2013 proposal defined the roles of the Centres as:

- provide assistance to the Commission, Member States, food chain actors and citizens regarding training, best practice, information and consumer communication;

- assess future legislative and policy proposals and their impact on animal welfare;

- assess animal welfare standards on the basis of the latest available knowledge; and

- co-ordinate a EU system for testing new techniques.

These proposed roles echoed those identified for the putative Network of Reference Centres proposed in an earlier strategy document (EC, 2012). In tandem with the 2013 proposal, DG SANCO $(2012 / 10293)$ defined a number of constraints within which the Network should operate i.e. it should: have only a co-ordinating role with no statutory powers; avoid duplicating work of existing Competent Authorities; be flexible enough to include new stakeholders and new Member States; and the annual budget should not exceed $€ 5.8 \mathrm{M}$.

However, to this point, there had been no detailed determinations on the organisational structure of the Network, in part perhaps, because there are several difficulties in doing so. First, the Network's internal environment is complex due to the nature and number of actors forming the Network, together with its multi-sectorial mission. Second, there are significant pre-defined constraints on the organisational structure (see list above), and third, the 'external' environment 
within which the Network has to operate is complex due to the large number of organisations outside the Network that could impinge on its activities but over which the Network may or may not be able to exercise any control (Palmer and Hartley, 2011).

Recognising these difficulties, DG SANCO commissioned a consortium of 16 universities and 10 research institutes from 16 Member States to evaluate alternative organisational structures for the Network using an appropriate and rigorous methodology and accommodating key functional requirements and political and economic constraints (Veissier et al., 2013). This Research Note reports on this work and describes the methodology used to review and evaluate alternative models of organisational structure andproposes an optimal organisational structure for the future EU Network of welfare Reference Centre.

Method

The study had two distinct stages (Veissier et al., 2013). Stage I reviewed and identified relevant organisations for use as 'organisational' models for the Network and created a criteriabased screening methodology to provide a shortlist for Stage II, the testing of the organisations for suitability.

At various points in the evaluation, informed decisions were taken on such issues as the choice of exemplar organisations and the identification of evaluation criteria and the ranking of their importance. Unless otherwise stated, these were made by an Expert Group composed of 47 animal welfare experts from a range of disciplines and stakeholders from national authorities, EU institutions, international welfare organisations, industry groups and NGOs. 
In Stage I, the structure of the 12 candidate organisations was mapped and evaluated. This involved judgements about the suitability of each structure for the work the Network will be required to do, plus the constraints specified by DG SANCO. The Expert Group identified and ranked organisations according to seven criteria focussed on their mission statements and 15 criteria assessing organisational function. Each of these were allocated a weight by the Expert Group reflecting their relative importance (Table 1).

Table 1 here

Stage II involved assessing the suitability of the structures of the three most prospective organisations shortlisted in Stage I. To do this, a suitable analytical technique had to be identified. It has been argued that the viability of an organisation, or organisational structure, cannot be understood without reference to the external 'environment' in which it operates (Duncan, 1972; Buchannan and Cribb, 1998). One of the most commonly used tools for such 'environmental' evaluations is the PEST framework (Aguilar, 1967), which defines the external environment of organisations in terms of Political, Ecconomic, Social and Iechnological dimensions. The PEST framework has become the mainstay of strategic planning, because it helps managers understand the context in which organisations do business (Glaister and Falshaw, 1999). PEST analysis involves three steps:

- determine factors within the PEST dimensions that impact on the operation of the organisation;

- $\quad$ identify (and collect) data relating to these (states, quantities, change directions); and

- draw conclusions from this on the impacts of different factors on the organisation.

PEST is the simplest form of this type of environmental scanning framework but has been variously extended to account for other dimensions of operating environments, such as the 
physical environment in PESTE analysis (Richardson, 2006) and legal considerations in PESTLE (Kolios and Read, 2013). PEST is, therefore, a very flexible evaluation framework that can be adapted to capture a range of dimensions of the environments in which organisations operate.

PEST is an ideal approach in this case as it is necessary to characterise the external environment in which the future Network would operate in terms of Political, Economic, Social and Technological dimensions. However, here we are required to consider not only the external environment in which the Network must operate i.e. in terms of the opportunities and constraints that this might present, but also its internal 'environment' reflected in the organisational constraints imposed by DG SANCO. (Veissier et al., 2013). Adding this 'organisational' dimension to the evaluation framework creates PESTO i.e. a more holistic framing of both the external and internal environment.

Perhaps the most tried and tested management planning approach used to evaluate the qualities of an organisation's internal environment, within the context of its external environment, is SWOT (or TOWS) analysis, whereby the external environment is characterised by Opportunities and Threats and the internal environment characterised by Strengths and Weaknesses (Weihrich, 1982). Some researchers have combined PEST and SWOT-type approaches to allow for a more nuanced and structured analysis than either approach would individually allow (see Srdjevic et al., 2012; and Yüksel, 2012). We adopt this same joint approach here, evaluating the Strengths and Weaknesses of internal organisational structures in the context of the PEST (external) and O (internal) environment dimensions. This evaluation framework is termed SWEPSOT. 
Within each of the economic, political, social, organisational and technical dimensions, a whole array of factors might potentially have some impact on the organisational requirements of the future Network. As a means to reducing this complexity, the subset of these factors deemed to be most influential was identified. This task was undertaken by the authors in combination with the project's Expert Group and is reported in full in Veissier et al. (2013). The results are presented in Table 2.

Table 2 here

The factors identified within each of the 'E', ' $P$ ', ' $S$ ', ' $O$ ' and ' $T$ ' dimensions obviously vary in the extent to which they impact on the Network's organisational requirements. A fully nuanced SWEPSOT analysis might, therefore, have attempted to apply weights to these factors to reflect their relative importance. However, such a weighting was not necessary here as the subset of factors identified were chosen on the basis that each was so important that good performance on each was essential for the adequate functioning of the future Network.

To undertake the SWEPSOT analysis, a contingency table was constructed for each organisational structure. Each table contained two columns (see Table 3) representing the strengths and weaknesses of the organisational structure (i.e. the internal environment) and five rows, representing the ' $E$ ', 'P', 'S' and ' $T$ ' dimensions of the external environment and the 'O' organisational constraints. While the strengths and weaknesses of each organisational structure on each of these five dimensions are identified, it should be remembered that the strength and weakness columns do not themselves represent two separate dimensions, but rather opposing ends of the same continuum. A weakness is, simply put, the absence of a strength. For this reason, it was not necessary to use both the strengths and weaknesses evaluation criteria in the process of identifying organisational structures that fail to deliver 
required functionality. Therefore, decisions on the relative suitability of different organisational structures was based on the number of weaknesses identified with each.

Results

Introduction

The 14 organisations selected for the Stage I screening were classified on the basis of their organisational structure, with three types identified: 'centralised'; 'specialised'; and 'distributed'. The characteristics of these typologies are described below. To avoid duplication, one representative organisation from each of these three typologies was then selected for the Stage II analysis. Full details of the strengths and weaknesses of each typology are given by Veissier et al. (2013).

Descriptions of the three organisational structure typologies

In the 'centralised' organisational structure (like the European Food Safety Authority), coordination of National Reference Centres $(\mathrm{RC})$ would be undertaken by one Co-ordinating Body (CB), probably an EU agency, that formulates strategy, leading to considerable harmonisation between RCs in each MS in terms of knowledge sharing etc. RCs would be pre-existing bodies dealing with welfare issues, such as state veterinary services or ministries of agriculture. RCs, covering all species and topics, would apply strategy formulated from the centre and send data (e.g. on compliance) in return. Temporary transnational working groups (WG) would be established to discuss issues beyond the remit of the $C B$, such as specific topics requiring scientific input or regional perspectives. Network operating costs, excluding special projects, 
would be largely incurred by the MS-funded RC. The CB would need an office with staff situated in one MS. EU costs for this Network would be 'medium' on a scale of low to high.

Under the 'specialised' organisational structure (e.g. the European Innovation Partnership) the $\mathrm{CB}$, as a service of the Commission, would coordinate a few RCs i.e. research or technical institutes which may have particular specialisations, such as a single livestock species (SP), or a multi-species issue (I). The CB would share knowledge with the RCs, set overall priorities and collect data. Each MS would nominate a national institution to interact with each RC. RCs would be new institutions, established in a few MS. Costs to the EU would be 'high' due to the requirement for centrally funded capital investment and operating costs for the RCs.

Under the 'distributed' structure (like the European Centre for Disease Prevention and Control), the $\mathrm{CB}$ would be a service of the Commission with a purely advisory role. There would be a RC in each MS, covering all species and topics with each setting their own priorities within a global strategy. Decision-making on strategy would be shared between the $\mathrm{CB}$ and all RCs, making exchanges between them frequent. RCs could be existing organisations, so infrastructure and operating costs would be covered by the MS. Networking would be implemented between stakeholders within MS, on specific projects. EU-incurred operating costs would be 'medium' due to the need to coordinate a large Network (i.e. workshops, travel).

SWEPSOT analysis of the organisational structure typologies

Using the SWEPSOT methodology, the three different organisational structures were evaluated in terms of the five dimensions of the operating environment (Veissier et al., 2013). This found that the top-down approach of the centralised organisational structure has benefits for harmonisation between MS in terms of identifying compliance problems and sharing knowledge. 
However, this arrangement has political and social weaknesses because engagement is weakened i.e. national RCs are unable to influence policies. There would be a social upside because the nationally-based RCs would ensure that implementation was sympathetic to local customs. While the Network would incur significant centralised costs due to the requirement to fund the CB and WGs, this could be reduced if the CB was located away from Brussels, and the RCs would be nationally funded. Politically, the location of the CB in one MS might be seen as controversial and thus be contested by other MSs.

The specialised structure has technical strengths in that RCs are research institutes. Political and social advantage is gained by sharing decision-making between the CB and the RCs. However, the political downside is that EU funding of the RCs could lead to the perception of centralised influence over priority setting, with RCs being simply mouthpieces. Nevertheless, this could represent a social strength if this is perceived to lead to an increase in trustworthiness and competence. Technical disadvantage may occur if geographical decentralisation of RCs leads to bias towards national self-interest. Additionally, this structure might be seen as inflexible as a new topic would require a new $\mathrm{RC}$ to be established.

The distributed structure has political and social benefits from the greater role that national RCs play in policy setting. However, there is a political and technical downside-risk that each national $\mathrm{RC}$ might develop their own strategies with little dissemination of best practice. Organisationally, the number of RCs would make coordination difficult.

Choosing an ideal organisational structure

Based on the analysis summarised above, the Expert Group concluded that each organisational typology had obvious weaknesses, and that these were severe enough that none of these 
typologies was suitable as a model for a future welfare Network. Therefore, an alternative approach (a 'Regional' typology) was developed, combining the best elements of the three exemplar typologies to maximise strengths and minimise weaknesses.

The centralised typology offers the benefits of technical harmonisation, through the actions of the $\mathrm{CB}$, but this creates negative political and social outcomes. However, these benefits are retained in the Regional typology, and the downside reduced, by making the CB semiautonomous i.e. comprising representatives of the Commission and $\mathrm{RC}$, rather than vesting control in an EC agency or service. There would be a network of five regionally-based RCs (see Figure 1) and their representatives would chair the $C B$ in biennial rotation. RCs would retain input to the CB via their representatives, but the CB would still carry out policy development, strategic planning and priority setting. CB decisions could be taken by qualified majority voting, in light of the extension of this practice in EU decision-making under the Lisbon Treaty (European Commission, 2007b).

Figure 1 here

The RCs would be knowledge providers co-ordinating dialogue and the flow of information between themselves and other actors in each MS. RCs would deal with all species and topics, but may also have some particular specialisation, thereby eliminating local bias towards single issues or species and keeping central costs down. This approach also retains the benefits of technical specialisation seen under the centralised and specialised typologies arising from regional or national clusters of expertise. 
Although localization of RCs provides weaker co-ordination benefits than the centralised typology, it still offers more in this regard than the distributed typology and will offer a good balance between providing freedom for local initiatives and the need for central co-ordination. Networking within regions would facilitate trust and confidence from Network users and the engagement of national stakeholders.

Devolvement of responsibility for dissemination and data collection to specialist RCs does mean some risk of fragmentation of activity and uneven performance, but implementation will be more sympathetic to local conditions. Effective support for regions from the CB would be necessary, through co-ordination of links between RCs to provide help to regions that currently do not have expertise on particular aspects of animal welfare. While CB operating costs would be minimal, this function being somewhat 'virtual' in nature, higher demands on EU finances would result from the establishment and operation of five new regional RCs. The EU-funding requirement for a Network with this organisational structure would, therefore, be 'high'.

Although the regional typology would not be the cheapest option, this structure, albeit a compromise, appears to offer the most strengths and fewest weaknesses of the options considered, as shown in Table 3.

Table 3 here

Discussion and conclusions

Whilst some have argued for PEST and SWOT-type analytical frameworks to be replaced by more 'modern' techniques (e.g. Hill and Westbrook, 1997), they continue to be the mainstay of corporate strategy development. The longevity of these approaches derives from their 
transparency, simplicity and flexibility. The policy planning exercise reported here has made full use of these advantages, first by amalgamating the PEST and SWOT techniques to create a bespoke analytical framework, then by embedding this within a larger resource and competency-based analytical process.

This multi-stage analytical process has provided a systematic framework through which expert stakeholders have been able to define the complex operating environment within which the putative Welfare Network would have to operate, together with the constraints arising within these dimensions. This has allowed a thoughtful balancing of the strengths and weaknesses of different organisational structures in relation to these dimensions.

Tensions between dimensions were found to be numerous. The need to achieve a balance between these has led to what might be seen as a technically sub-optimal outcome. However, the need to account for political constraints in this assessment makes technically sub-optimal solutions unavoidable. Policy decision-making in the EU must deal with rather partisan views, where national interests are at stake in the allocation of resources and the establishment of new institutions, or institutional roles. The SWEPSOT-based assessment process accommodates this political 'challenge'.

The typology-based approach used here to characterise organisational structures was flexible enough to allow the de-composition of functional units within organisational typologies, making it possible to isolate 'ideal' functional units, so that these could be combined into a novel, bespoke, organisational structure for the future Network i.e. the regional typology.

The use of the SWEPSOT framework has solved a complex optimisation problem in identifying an organisational structure that delivers multiple outputs, making best use of limited resources, 
subject to a set of economic, political, organisational, social and technical constraints. The fact that the SWEPSOT framework, has facilitated the design of an optimal organisational structure, within such a complex and constraining set of environmental conditions, suggests that this evaluation framework would be suitable for use in the design of other complex EU institutions that also have to operate in highly complex and constraining environments, or the evaluation of existing EU institutions to identify options for increasing their organisational efficiency.

Societal concern for the welfare of farmed animals continues to grow and is most visibly expressed in public outrage at media exposure of failures to meet minimum welfare standards in livestock production, transport and slaughter and continued calls, often voiced through campaigning groups, for yet higher welfare standards to be reflected in new legislation. The EU and MS governments recognise this pressure for change in their animal welfare strategy documents, for example the 'Animal Health and Welfare Strategy for Great Britain' (Defra, 2004) which described the current state of farmed animal health and welfare as 'neither adequate or sustainable'. EU policy-makers are, therefore, faced with the challenge of responding to these demands for higher welfare in a way that does not unduly disadvantage EU livestock producers, who are already facing fierce competition for market share from lower-cost producers outside the EU, such as Brazil and Thailand. However, rather than legislate to create an uplifted welfare 'floor', EU policy-makers have recognised that sustainable welfare improvements would be best achieved through market-based measures. It is also recognised that for this to be delivered, further increases in the welfare capacity of the food chain are necessary. Such capacity building requires the construction of alliances among a wide range of organisations with an interest in livestock production, the food chain and animal welfare, based on a shared understanding of goals, co-ordinated efforts and complementary roles. 
While it would be unreasonable to suggest that further improvement in animal welfare in the EU is dependent on the creation of a Network of welfare RCs, this goal would certainly be advanced by such a Network, as a means to identifying and remedying bottlenecks in welfare policy implementation and widening the uptake of best practice. As Blokhuis et al. (2013) have commented, 'Given that there is considerable variation both in environmental and production practices within Europe and that specific expertise is available in different Member States, such a Network could clearly create valuable synergies and could benefit from the consideration and/or incorporation of existing national practices and information'. The existence of numerous Networks of reference centres with similar functions in other spheres, certainly attests to the proven capacity enhancing benefits that such Networks can provide (Fraser et al., 2009).

\section{Reflections at October 2016}

Recent developments in the EU i.e. the 'Brexit' vote in the UK, have highlighted the requirement for the Network to have a structure flexible enough to accommodate the involvement of both new EU and non-EU members. Withdrawal from the EU certainly does not preclude the possibility of UK membership of the Network. The UK has been a world leader in promoting the welfare of farmed animals and the UK government 10-year strategy document (Defra, 2004) signalled a policy aspiration to continue to achieve world-leading standards of farmed animal health and welfare. In light of this, it is not unreasonable to suppose that the UK might seek to join the welfare Network to secure a number of benefits such as co-ordination and integration of research activity and sharing of best practice etc. Should the post Brexit UK seek membership of the Network, the organisational framework proposed here is flexible enough to permit this, conditional upon a very modest contribution to administrative costs, although it is unlikely that the UK would be able to host one of the RCs. Access might also be available to other non-EU states. 
It hardly seems necessary to argue the case that the study reported here addressed a very real policy need. However, one uncertainty remains i.e. does the recommendation arising from this analysis provide an optimal and politically acceptable organisational structure for the Welfare Network? Ultimately, this question will only be answered when policy-makers take their final decision to establish the Network of Welfare Centres and agree on the organisational structure that the Network will have. At the time of writing, the Regulation to provide the legal basis for the establishment of the Centres has still not been produced. However, there have been some policy developments towards this goal. For example, the Committee on the Environment, Public Health and Food Safety accepted a report (European Parliament, 2014) amending the wording of Article 95 to state that the Commission 'WILL' designate RCs rather than the former 'MAY'. It is, therefore, quite certain that at some point in the near future, possibly in 2017, the Regulation required to establish the Network will be put before the Commission, Council and Parliament. The discussions leading to the production of this are still ongoing and the study reported here will contribute to that debate. We are confident that through the use of this particular analytical framework, an organisational structure has been identified, from among a number of alternatives, that stands the best chance of meeting the prescribed requirements for the Welfare Network, and the constraints within which it must operate. At the very least, the analysis reported here should provide EU policy-makers with a wealth of relevant data and understandings on which an informed policy choice can be based.

\section{References}

Aguilar, F.J. (1967) Scanning the Business Environment. (New York: Macmillan). 
Bennett, R.M. and Appleby, M. (2010) ‘Animal welfare policy in the European Union'. In Oskam, A., Meester, G. and Silvis, H. (eds) EU Policy for Agriculture, Food and Rural Areas. (Wageningen, The Netherlands: Wageningen Academic Publishers), pp. 243-252.

Blokhuis, H., Miele, M., Veissier, I. and Jones, B. (eds) (2013) 'Improving farm animal welfare science and society working together: the Welfare Quality approach'. (Wageningen, The Netherlands: Wageningen Academic Publishers).

Broom, D.M. (1991) 'Animal welfare: concepts and measurement'. Journal of Animal Science, Vol. 69, pp. 4167-4175.

Buchannan, D. and Cribb, F. (1998) 'The information audit: an integrated strategic approach'. International Journal of Information Management, Vol. 18, pp. 29-47.

Defra (2004) Animal Health and Welfare Strategy for Great Britain. (London: Defra).

Duncan, R.B. (1972) 'Characteristics of organizational environments and perceived environmental uncertainty'. Administrative Science Quarterly, Vol. 17, pp. 313-327.

European Commission (2006) 'Community action plan on the protection and welfare of animals 2006-2010'. COM(2006)13. (Brussels: CEC).

European Commission (2007a) 'Attitudes of EU citizens towards animal welfare'. Special Eurobarometer 270/Wave 66.1. (Brussels: CEC). 
European Commission (2007b) 'Treaty of Lisbon - Amending the treaty on European Union and the treaty establishing the European Community'. Official Journal of the European Union, 2007/C 306/01.

European Commission (2009) 'Options for animal welfare labelling and the establishment of a European Network of Reference Centres for the protection and welfare of animals'. COM(2009) 584 final. (Brussels: CEC).

European Commission (2012) 'EU strategy for the protection and welfare of animals, 20122015'. $\operatorname{COM(2012)~6.~(Brussels:~CEC).~}$

European Commission (2013) 'Regulation on official controls on a reference centre for animal welfare are set-up to support the activities of the Commission'. COM(2013) 265. (Brussels: CEC).

European Parliament (2009) 'Evaluation and assessment of the Animal Welfare Action Plan, 2006-2010'. 2009/2202(INI). (Brussels: European Parliament Committee on Agriculture and Rural Development).

European Parliament (2014)

http://www.europarl.europa.eu/sides/getDoc.do?pubRef=-//EP//TEXT+REPORT+A7-2014-

$\underline{0162+0+D O C+X M L+V 0 / / E N}$

FAWC (2009) 'Farm Animal Welfare in Great Britain: Past, Present and Future'. (London: Farm Animal Welfare Council). 
Fraser, D., Kharb, R.M., McCrindle, C., Mench, J., Paranhos da Costa, M., Promchan, K., Sundrum, A., Thornber, P., Whittington, P. and Song, W. (2009) 'Capacity building to implement good animal welfare practices'. Report of the Expert Meeting at FAO Headquarters, 30 September - 3 October 2008. (Rome, Italy: FAO).

Glaister, K.W. and Falshaw, J.R. (1999) 'Strategic planning: still going strong?'. Long Range Planning, Vol. 32, pp. 107-116.

Hill, T. and Westbrook, R. (1997) 'SWOT analysis: it's time for a product recall'. Long Range Planning, Vol. 30, pp. 46-52.

Kolios, A. and Read, G. (2013) 'A political, economic, social, technical, legal and environmental (PESTLE) approach for risk identification of the tidal industry in the United Kingdom'. Energies, Vol. 6, 5023-5045.

Mancini, M.C. and Arfini, F. (2012) 'Consumer Communication and Organisational Strategies for Animal Welfare by the Food Industry and Retailing in Italy'. Eurochoices, Vol. 12, No. 2, pp. 5056.

Palmer, A. and Hartley, B. (2011) The Business Environment, 7th edn, (London: McGraw-Hill Higher Education).

Richardson, Jr. J.V. (2006) 'The library and information economy in Turkmenistan'. IFLA Journal, Vol. 32, 131-139. 
Srdjevic, Z., Bajcetic, R. and Srdjevic, B. (2012) 'Identifying the Criteria Set for Multicriteria Decision Making Based on SWOT/PESTLE Analysis: A Case Study of Reconstructing A Water Intake Structure'. Water Resources Management, Vol. 26, pp. 3379-3393.

Veissier, I., Spinka, M, Bock, B., Manteca, X. and Blokhuis, H. (2013) 'Recommendations for the establishment of a coordinated European network for animal welfare'. Deliverable 6. December 22, 2013. http://www.euwelnet.eu/euwelnet/53431/7/0/80

Weihrich, H. (1982) 'The TOWS matrix: a tool for situational analysis'. Long Range Planning, Vol. 15. No. 2, pp. 54-66.

Yüksel, İ. (2012) 'Developing a Multi-Criteria Decision Making Model for PESTEL Analysis'. International Journal of Business and Management, Vol. 7, No. 24, pp. 52-66. 
Table 1: Criteria used to assess the functioning of existing models of pan-European networks.

\begin{tabular}{rlc}
\hline & \multicolumn{1}{c}{ Criteria } & Weight \\
\hline 1. & Has solely a co-ordinating role. It is not a Competent Authority. & 8 \\
2. Avoids duplication of work/roles (e.g. between Competent Authority, DG-SANCO...). & 4 \\
3. Networks all existing national and transnational organisations and stakeholder groups. & 4 \\
4. Cost of running the Network (budget does not exceed $€ 5.8$ million). & 2 \\
5. Is financially supported by several sources. & 2 \\
6. Organisational structure can cope with addition of new stakeholder organisations. & 1 \\
7. Organisational structure can cope with addition of new members. & 8 \\
8. Is capable of broadening its scope in future (e.g. inclusion of zoo, companion and & 8 \\
9. $\quad$ Organisational structure allows for collaboration with non-EU member countries. & 4 \\
10. Organisational structure allows for integration of private and public stakeholder groups. & 1 \\
11. Can be proactive as well as reactive. & 8 \\
12. Monitors efficiency and efficacy of own knowledge transfer activities. & 4 \\
13. Has a relatively low administrative burden (on all parties). & 2 \\
14. Has a high level of reactivity (e.g. non-compliance is rapidly detected and the Network & 4 \\
15. Stimulates knowledge exchanges on the issue of animal welfare, leading to innovation. & 4 \\
\hline
\end{tabular}

Source: Veissier et al. (2013). 
Table 2. Factors identified as impacting on the suitability of the organisational structures of the short-listed co-ordinating organisations.

\begin{tabular}{|c|c|}
\hline Dimension & Factors \\
\hline Political & $\begin{array}{l}\text { Co-ordinating Body/Management Board location } \\
\text { Direct/indirect involvement of national actors } \\
\text { Legal status of the Co-ordinating Body (independent/EU service) } \\
\text { Strategy setting (centralised /decentralised) } \\
\text { Top-down/bottom-up decision-making approaches }\end{array}$ \\
\hline Economic & $\begin{array}{l}\text { Cost of the Network } \\
\text { Funding (EU/Member States) }\end{array}$ \\
\hline Social & $\begin{array}{l}\text { Ability to capture cultural differences and to tailor training and information to } \\
\text { local conditions } \\
\text { Active/reactive engagement of national actors } \\
\text { Direct/Indirect engagement of national representatives in decision making } \\
\text { Emphasis on societal concerns } \\
\text { Enabling stakeholders' trust }\end{array}$ \\
\hline Technical & $\begin{array}{l}\text { Exchange of knowledge between actors } \\
\text { Level of scientific expertise }\end{array}$ \\
\hline Organisational & $\begin{array}{l}\text { Effectiveness } \\
\text { Flexibility (in terms of composition, functioning and themes covered) }\end{array}$ \\
\hline
\end{tabular}

Source: Veissier et al. (2013). 
Table 3: The SWEPSOT analysis of the strengths and weaknesses of the regional organisational structure.

\begin{tabular}{|c|c|c|}
\hline \multicolumn{2}{|r|}{ Strengths } & Weaknesses \\
\hline 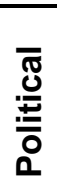 & $\begin{array}{ll} & 7 \text { year rotation of RCs } \\
\checkmark & \text { Link with the Commission (DG SANCO) with a } \\
& \text { major influence on policy }\end{array}$ & $\begin{array}{l}\checkmark \text { Network perceived as an arm of EU } \\
\text { enforcement and, therefore, not neutral } \\
\checkmark \quad \text { CB has no statutory powers but just a } \\
\text { co-ordination and advisory role }\end{array}$ \\
\hline 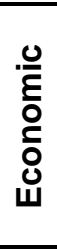 & $\begin{array}{ll} & \text { RC and national partner institutes may be pre- } \\
\text { existing organisations situated in MS } \\
\checkmark \quad \text { Most dissemination and training carried out by } \\
\text { national partner institutes and therefore funded } \\
\text { by non-EU (national) sources } \\
\checkmark \quad \text { Low administrative burden and costs } \\
\end{array}$ & \\
\hline $\begin{array}{l}\overline{\bar{\pi}} \\
\bar{\delta} \\
\text { க) }\end{array}$ & $\begin{array}{l}\text { The prominent involvement of DG SANCO may } \\
\text { lead to increased stakeholder trust } \\
\checkmark \text { Active engagement of national stakeholders } \\
\text { who provide input through national institutes }\end{array}$ & \\
\hline 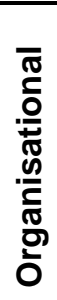 & $\begin{array}{l}\checkmark \text { Weaknesses of both the centralised and } \\
\text { decentralised approach are minimised by a } \\
\text { mixed approach based on } 5 \text { regional sub- } \\
\text { Networks. } \\
\checkmark \text { The structure allows for high reactivity in finding } \\
\text { technical solutions }\end{array}$ & $\begin{array}{ll}\checkmark \text { Risk of fragmentation and isolation } \\
\end{array}$ \\
\hline 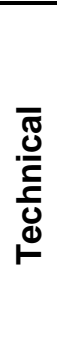 & $\begin{array}{l}\checkmark \text { Quick and simple exchange of knowledge and } \\
\text { information among members in each sub- } \\
\text { network and between sub-networks } \\
\checkmark \quad \text { Decentralisation of knowledge transfer and } \\
\text { training performed by national partner institutes } \\
\text { can capture local conditions } \\
\checkmark \quad \text { Rotation of RCs stimulates scientific excellence } \\
\text { and efficiency } \\
\checkmark \text { Regional structure reduces language barriers }\end{array}$ & $\begin{array}{l}\checkmark \text { Region-based RCs might be weak on } \\
\text { some specific topics/issues }\end{array}$ \\
\hline
\end{tabular}

Source: Veissier et al. (2013). 
Figure 1: The regional organisational structure chosen for the Network.

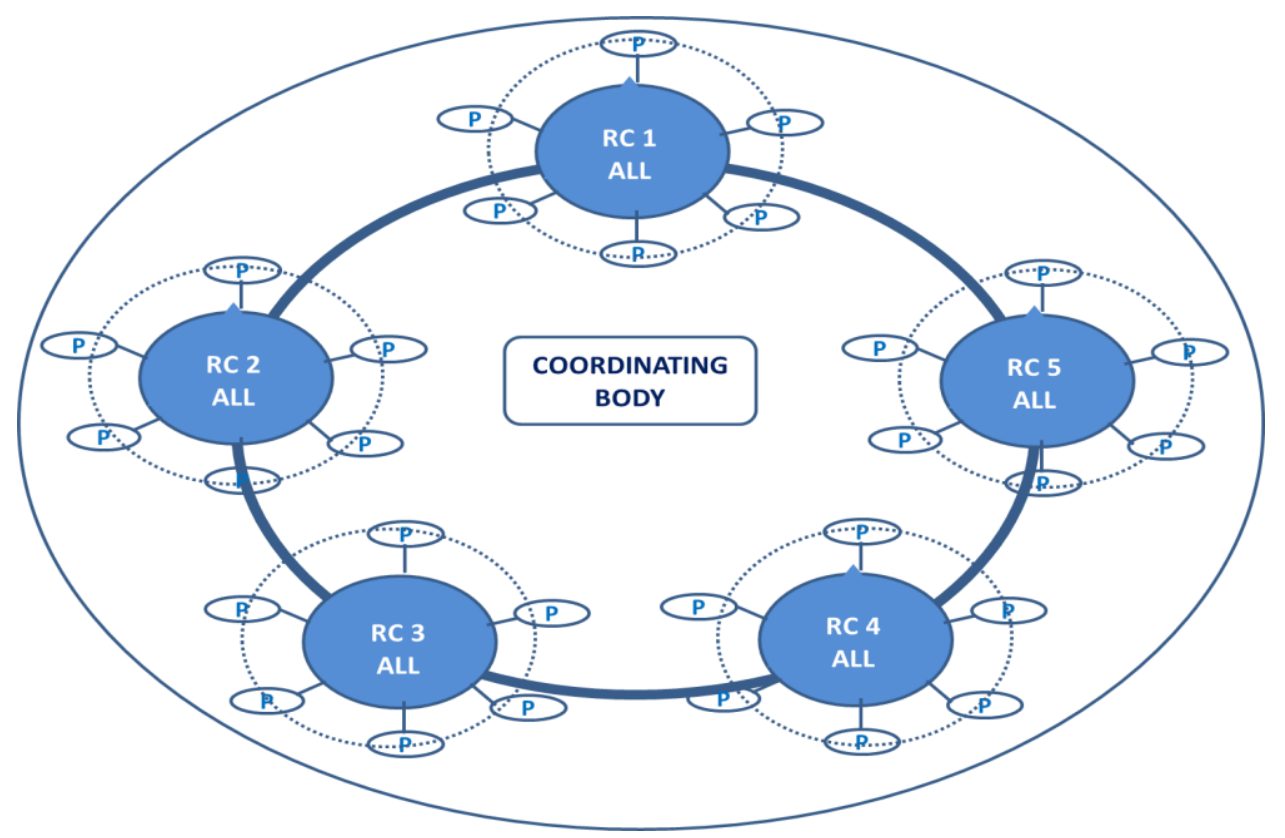

Key:

$\mathrm{RC}=$ Reference Centre; $\mathrm{ALL}=$ coverage of all species and topics; $\mathrm{P}=$ partners.

Source: Veissier et al. (2013). 